\title{
The effect of a well-resolved stratosphere on East Asian winter climate
}

\author{
Ke Wei ${ }^{1}$ (i) $\cdot$ Zelin Cai $^{1,2} \cdot$ Wen Chen ${ }^{1} \cdot$ Luyang $\mathrm{Xu}^{1,2}$
}

Received: 13 June 2016 / Accepted: 15 October 2016 / Published online: 3 November 2016

(C) The Author(s) 2016. This article is published with open access at Springerlink.com

\begin{abstract}
This study performs a comparison between models with and without well-resolved stratosphere on the simulation of the East Asian winter climate. The results reveal that the Fifth Coupled Model Inter-comparison Project (CMIP5) models with model top above the stratopause have a better simulation of the distribution of surface air temperature, sea level pressure and precipitation than the models with a low-top below the stratopause. The discrepancy of the East Asian winter climate between high-top (HT) and low-top (LT) CMIP5 models is also evident in the future projection under higher (RCP85) and midrange (RCP45) emission scenarios. The HT models present about 1.3 and $1.7^{\circ} \mathrm{C}$ higher surface air temperature in East Asian region under RCP45 and RCP 85 scenarios by the end of this century than that of the LT models. Therefore, the insufficient representation of the stratosphere may lead to underestimation of the anthropogenic global warming in regional scale and hence have the potential to lead to insufficient response action and mitigation measures.
\end{abstract}

This paper is a contribution to the special issue on East Asian Climate under Global Warming: Understanding and Projection, consisting of papers from the East Asian Climate (EAC) community and the 13th EAC International Workshop in Beijing, China on 24-25 March 2016, and coordinated by Jianping Li, Huang-Hsiung Hsu, Wei-Chyung Wang, Kyung-Ja Ha, Tim Li, and Akio Kitoh.

Ke Wei

weike@mail.iap.ac.cn

1 Center for Monsoon System Research, Institute of Atmospheric Physics, Chinese Academy of Sciences, Zhong-Guan-Cun, Haidian District, P.O. Box 2718, Beijing 100190, China

2 University of Chinese Academy of Sciences, No.19A Yuquanlu, Beijing 100049, China
Keywords East Asian winter monsoon · CMIP5 · Projection $\cdot$ Stratosphere

\section{Introduction}

The stratosphere is conventionally believed to be passively influenced by the tropospheric circulation anomalies. This upward effect has been well documented in observational and theoretical studies of stratospheric phenomena such as stratospheric sudden warming (e.g., Holton and Mass 1976; Labitzke 1982; Matsuno 1971) and quasi-biennial oscillation (e.g., Baldwin et al. 2001; Holton and Lindzen 1972; Lindzen and Holton 1968; Plumb 1977). However, studies in the recent decades have revealed that stratosphere can play an important role in the near surface climate change. For example, data diagnosis showed that the stratosphere zonal-mean zonal wind anomalies can propagate poleward and downward to the troposphere consecutively from the stratopause region (Christiansen 2001; Kodera 1995; Kuroda and Kodera 1999). It was further illustrated that the anomalous Arctic Oscillation (AO) signal, which is the dominant mode of the geopotential fields north of $20^{\circ} \mathrm{N}$, appears firstly in the upper stratosphere, and propagates all the way down to the troposphere and can have significant influence on the surface extended-range weather and shortterm climate (Baldwin and Dunkerton, 1999, 2001; Baldwin et al., 2003b; Moritz et al., 2002). It's believed that " $a t$ its maximum, the magnitude and geographic scale of this influence may be comparable to that of El Niño-Southern Oscillation" (Baldwin et al. 2003a).

The influence from the stratosphere has been verified in numerical studies. For example, in a long-term (260 years pre-industrial control run) simulation performed with the CMCC-CMS climate model including a state-of-the-art 
stratosphere, Manzini et al. (2012) showed that the sea level pressure, surface temperature, sea ice cover and the Atlantic meridional overturning circulation anomalies in the Northern Hemispheric mid and high latitudes can be traced back to the long lasting stratospheric vortex anomalies in the inter-decadal time scales. Karpechko and Manzini (2012) found that the early winter (November-December) stratospheric changes in response to the increased $\mathrm{CO}_{2}$ concentration could propagate downward and have the largest influence on the surface during mid and late winter (January-March). The association between the strength of stratospheric polar vortex (SPV) and East Asian winter monsoon was discovered in several studies (Wei and Bao 2012; Wei et al. 2015). The second leading mode of the surface air temperature in East Asia (EA), with opposite changes between the northern EA and the southern EA, is highly correlated with the strength of stratospheric polar vortex. And the diagnosis of multiple reanalysis datasets shows that the relationship between the SPV and the second EAWM (East Asian winter monsoon) mode increased since the late 1980s (Wei et al. 2015).

Climate models have become one of the primary tools in climate research as they help to improve our understanding on mechanism, prediction and adaption to climate change. Significant progress has been made in incorporating more realistic physical and chemical processes in the models. Meanwhile, current models are constructed on a finer spatial grid. However, the model progress in the stratosphere seems relatively slow. In the models which were used in the fourth climate change assessment report (AR4) of the Intergovernmental Panel on Climate Change (IPCC), half of the model have model top beneath $2 \mathrm{hPa}$ (upper stratosphere around $48.5 \mathrm{~km}$ ). These models show a significant cold bias in their upper levels $(\sim 10 \mathrm{hPa})$ compared to the reanalysis data, possibly due to low model top or insufficient stratospheric levels (Cordero and Forster 2006). In the most recent fifth assessment report (AR5) of the IPCC, 54 models were used for the assessment, among which only half (27) models have full stratosphere with model lid top above $1 \mathrm{hPa}$. These low-top models have weaker polar vortex variability, and reduced planetary wave activity in stratosphere, leading to much less frequency of major sudden stratospheric warming events in the stratosphere (Charlton-Perez et al. 2013; Osprey et al. 2013). The Climate-system Historical Forecast Project using 16 coupled models ( 8 high-top models and 8 low-top models) shows that the high-top models have a more realistic stratospheric response to El Nino and the QBO, and have a possible stratospheric pathway that enhance the wintertime prediction skill over high latitudes and North Atlantic region (Butler et al. 2016). The comparison study by Scaife et al. (2012) showed that the inclusion of full stratosphere in the Hadley Centre Global Environmental Model (HadGEM) and the ECHO-G Middle Atmosphere Model (EGMAM) could lead to the changes in regional wind and rainfall patterns, which are large enough to significantly alter the regional climate change projection. Hence, it is crucial to incorporate a fully resolved stratosphere in the models to get better near surface climate change simulations.

For the densely populated and economic booming East Asia region, climate variation of even moderate amplitude can have profound impact. There have been several evaluation studies with focus on the model reproduction of East Asian summer and winter monsoon climate (e.g., Boo et al. 2011; Gong et al. 2014; Wei and Bao 2012; Wei et al. 2014). It was shown that in the winter season, the current state-of-the-art CMIP5 models have the ability to reproduce circulation in EA region and progress had been made to relieve the surface cold bias, which was observed in the CMIP3 model ensemble. Meanwhile, CMIP5 models show more model consistence in most EAWM parameters (Wei et al. 2014, hereafter WEI14). However, it's still not clear whether the inclusion of a full stratosphere can make a better simulation of the climate in the East Asian region. And it's also necessary to reevaluate the future climate projection in this region, considering that with or without a full stratosphere may lead to significant climate change difference, which can be large enough to alter the regional climate change projection.

In this study, we examine the performance of the CMIP5 models with a well-resolved stratosphere in East Asian region, and compare with the models with a low model top. We also evaluate the effect of a well-resolved stratosphere on the regional climate change projection. As the stratosphere is mainly coupled with troposphere and have largest climate effect in winter season (Baldwin et al. 2003a, b), the study in this paper focuses mainly in the winter season. The layout of this paper is as follows. In Sect. 2, we will discuss the models and observation-based data used. In Sect. 3, CMIP5 EAWM climatology will be presented and comparison will be made between models with and without full stratosphere. Section 4 presents the discrepancy of the EAWM parameters/indices between high-top and lowtop CMIP5 Models. In Sect. 5, the regional climate change projection to the end of this century will be presented. We will present discussions and summaries in Sect. 6.

\section{Models and data}

\subsection{Data}

The monthly mean data of National Centers for Environmental Prediction-National Center for Atmospheric Research (NCEP-NCAR) Global Reanalysis 1 (Kalnay et al. 1996; Kistler et al. 2001) and the NOAA's 
Precipitation Reconstruction Dataset (Chen et al. 2002) were used in this study, including surface air temperature (SAT), sea level pressure (SLP), zonal wind (u) and meridional wind (v) at $1000 \mathrm{hPa}$ (UV1000), and zonal wind at $200 \mathrm{hPa}$ (U200). Our analyses are focused on the boreal winter. Therefore, the wintertime mean was computed by averaging 3-month periods (December-February (DJF)) in each year. Finally, the climatological wintertime means were calculated by averaging each DJF over the period of model experiments. To compare with CMIP3 and CMIP5 model output, the climatology is made in the period of 1970/71-1999/2000. It should be noted that the use of other observation-based reanalysis, such as the EAR-40 from European Centre for Medium-Range Weather Forecasts, or the Japanese 55-year Reanalysis (JRA-55), leads to the same result. We also used the monthly mean temperature data of 160 stations from China Meteorological Administration for comparison. The same results were obtained (figures not shown).

\subsection{CMIP5 models and experiments}

Model Intercomparison Projects (MIPs) provide the best opportunity to evaluate how the current state-of-the-art climate models characterize the variability of the climate system. The most conspicuous MIP is probably the Coupled Model Intercomparison Project (CMIP), which compare simulations from global coupled climate models with its components describing the atmosphere, ocean, sea ice and land surface, and provide a standard set of model simulations aiming to evaluate how well the models simulate and project the future climate change and understand some of the factors responsible for the differences in model projections (http://cmip-pcmdi.llnl.gov/cmip5/). The simulation results were used in the climate change assessment report of IPCC. Since its inception in 1995, CMIP has now evolved to the fifth phase (CMIP5), which was widely used in the fifth assessment report of the IPCC.

In this study, we adopted 42 couple climate model outputs from the Program for Climate Model Diagnosis and Intercomparison (PCMDI, http://cmip-pcmdi.llnl.gov/). The names of the analyzed models are listed in Table 1, together with the model resolution of the atmosphere. Table 1 is compiled using information that the participating modeling centers provided to the PCMDI (see http://wwwpcmdi.llnl.gov/ipcc/about_ipcc.php for more information about the models). As stratosphere can provide an important source of model improvement, models are divided into two groups based on whether the full stratosphere is resolved. If the model lid top is higher than stratopause $(1 \mathrm{hPa})$, it belongs to the high-top (HT) group; otherwise it is a low-top (LT) model. Accordingly, there are $20 \mathrm{HT}$ models and 22 LT models utilized in this study.
We used long-term experiments of the historical, RCP4.5 and RCP8.5, three core simulations of CMIP5. Historical experiments are forced by observed atmospheric composition changes and including time-evolving land cover, and designed to inspect how well the model can reproduce the main aspects of the characteristics and variations of historical climate. RCPs (Representative Concentration Pathways) experiments are designed as future projection simulations forced by specific concentrations. The RCP4.5 represents additional radiative forcing increase to a level of about $4.5 \mathrm{~W} / \mathrm{m}^{2}$ in 2100 which is a midrange mitigation emission scenario, and the RCP8.5 is a high emission scenario with an additional radiative forcing increasing to about $8.5 \mathrm{~W} /$ $\mathrm{m}^{2}$ in 2100 (Taylor et al. 2012). The output parameters from CMIP5 models, including surface air temperature, precipitation rate, meridional wind at $1000 \mathrm{hPa}$, sea level pressure, geopotential height at $500 \mathrm{hPa}$, zonal wind in at $200 \mathrm{hPa}$, are used and compared with the observation.

To compare with previous version of CMIP and confirm the model progress, the model output from 24 CGCM, released by CMIP3 and used for the AR4 evaluation, are used in this study. The model names of the CMIP3 models are listed in Table 2. These model results were made available by the IPCC Data Distribution Center (ftp://ftp-esg. ucllnl.org) and the Hadley Centre for Climate Prediction and Research. To be consistent with the reanalysis datasets, all of the CMIP3 and CMIP5 simulation results were regrided to a horizontal grid resolution of $2.5^{\circ} \times 2.5^{\circ}$ and focused on the winter (DJF) period.

\section{The model climatology of EAWM}

The comparison of CMIP5 historical run, RCP4.5 run and RCP8.5 run between HT and LT models, together with the NCEPR1 reanalysis and CMIP3 20C3 M run, is made for the mean state of winter (DJF) SAT (represented by $0{ }^{\circ} \mathrm{C}$ isotherm, Fig. 1a) and SLP (represented by the $1026 \mathrm{hPa}$ isobar, Fig. 1b). Multi-model ensemble (MME) is made for each group. Black contours are for NCEPR1 reanalysis and purple solid contours are for CMIP3 models. The dashed contours are for the low-top models. As pointed out by WEI14, the CMIP5 models are capable of simulating a good and reasonable EAWM feature and great improvement has been obtained in characterizing the regional climatology, compared with the previous CMIP3 models. The $0{ }^{\circ} \mathrm{C}$ isotherms in CMIP5 are more northward and close to both the reanalysis and station observation (Fig. 1a of WEI14). Although the CMIP5 LT models have a better SAT simulation than that of the CMIP3 models, the CMIP HT models shows a much greater improvement. The $0{ }^{\circ} \mathrm{C}$ isotherm of HT models (solid green contour) are almost overlapping with the NCEPR1 reanalysis (black contour), while 
Table 1 Information of the CMIP5 (IPCC-AR5) coupled models used in this study

\begin{tabular}{|c|c|c|c|c|c|}
\hline Model No & Model name & Institute and country & $\begin{array}{l}\text { Atmospheric model resolution } \\
(\text { lon } \times \text { lat })\end{array}$ & Atmospheric model lid top & $\mathrm{L} / \mathrm{H}$ top \\
\hline 1 & CanCM4 & CCCMA, Canada & $1.875^{\circ} \times 1.875^{\circ}$ & $0.5 \mathrm{hPa}$ & High \\
\hline 2 & CanESM2 & CCCMA, Canada & $1.875^{\circ} \times 1.875^{\circ}$ & $0.5 \mathrm{hPa}$ & High \\
\hline 3 & CESM1-WACCM & NSF-DOE-NCAR, USA & $1.9^{\circ} \times 2.5^{\circ}$ & $5.1 \times 10^{-6} \mathrm{hPa}$ & High \\
\hline 4 & CMCC-CESM & CMCC, Italy & $3.75^{\circ} \times 3.75^{\circ}$ & $0.01 \mathrm{hPa}$ & High \\
\hline 5 & CMCC-CMS & CMCC, Italy & $1.875^{\circ} \times 1.875^{\circ}(\mathrm{T} 63)$ & $0.01 \mathrm{hPa}$ & High \\
\hline 6 & GFDL-CM3 & GFDL, USA & $\sim 1.8^{\circ} \times 1.8^{\circ}$ & $0.01 \mathrm{hPa}$ & High \\
\hline 7 & GISS-E2-H & NASA GISS, USA & $2.5^{\circ} \times 2.0^{\circ}$ & $0.01 \mathrm{hPa}$ & High \\
\hline 8 & GISS-E2-R & NASA GISS, USA & $2.5^{\circ} \times 2.0^{\circ}$ & $0.01 \mathrm{hPa}$ & High \\
\hline 9 & GISS-E2-R-CC & NASA GISS, USA & $2.5^{\circ} \times 2.0^{\circ}$ & $0.01 \mathrm{hPa}$ & High \\
\hline 10 & HadGEM2-CC & MOHC, UK & $1.875^{\circ} \times 1.25^{\circ}$ & $85 \mathrm{~km}$ & High \\
\hline 11 & IPSL-CM5A-LR & IPSL, France & $1.9^{\circ} \times 3.75^{\circ}$ & $0.04 \mathrm{hPa}$ & High \\
\hline 12 & IPSL-CM5A-MR & IPSL, France & $1.25^{\circ} \times 2.5^{\circ}$ & $0.04 \mathrm{hPa}$ & High \\
\hline 13 & IPSL-CM5B-LR & IPSL, France & $1.9^{\circ} \times 3.75^{\circ}$ & $0.04 \mathrm{hPa}$ & High \\
\hline 14 & MIROC4 h & MIROC, Japan & $0.5625^{\circ} \times 0.5625^{\circ}(\mathrm{T} 213)$ & $0.9 \mathrm{hPa}$ & High \\
\hline 15 & MIROC-ESM & MIROC, Japan & $2.8125^{\circ} \times 2.8125^{\circ}(\mathrm{T} 42)$ & $0.0036 \mathrm{hPa}$ & High \\
\hline 16 & $\begin{array}{l}\text { MIROC-ESM- } \\
\text { CHEM }\end{array}$ & MIROC, Japan & $2.8^{\circ} \times 2.8^{\circ}$ & $0.0036 \mathrm{hPa}$ & High \\
\hline 17 & MPI-ESM-LR & MPI-M, German & $1.9^{\circ} \times 1.9^{\circ}(\mathrm{T} 63)$ & $0.01 \mathrm{hPa}$ & High \\
\hline 18 & MPI-ESM-MR & MPI-M, German & $1.9^{\circ} \times 1.9^{\circ}(\mathrm{T} 63)$ & $0.01 \mathrm{hPa}$ & High \\
\hline 19 & MPI-ESM-P & MPI-M, German & $1.9^{\circ} \times 1.9^{\circ}(\mathrm{T} 63)$ & $0.01 \mathrm{hPa}$ & High \\
\hline 20 & MRI-CGCM3 & MRI, Japan & $1.1^{\circ} \times 1.1^{\circ}(\mathrm{TL} 159)$ & $0.01 \mathrm{hPa}$ & High \\
\hline 21 & ACCESS1-0 & CAWCR, Australia & $1.875^{\circ} \times 1.25^{\circ}$ & $39 \mathrm{~km}$ & Low \\
\hline 22 & ACCESS1-3 & CAWCR, Australia & $1.875^{\circ} \times 1.25^{\circ}$ & $39 \mathrm{k} \mathrm{m}$ & Low \\
\hline 23 & BCC-CSM1 & BCC, China & $2.8^{\circ} \times 2.8^{\circ}$ & $2.97 \mathrm{hPa}$ & Low \\
\hline 24 & BNU-ESM & BNU, China & $2.8^{\circ} \times 2.8^{\circ}(\mathrm{T} 42)$ & $2.19 \mathrm{hPa}$ & Low \\
\hline 25 & CCSM4 & NCAR, USA & $0.9^{\circ} \times 1.25^{\circ}$ & $2.19 \mathrm{hPa}$ & Low \\
\hline 26 & CESM1-BGC & NSF-DOE-NCAR, USA & $0.9^{\circ} \times 1.25^{\circ}$ & $2.19 \mathrm{hPa}$ & Low \\
\hline 27 & CESM1-CAM5 & NSF-DOE-NCAR, USA & $0.9^{\circ} \times 1.25^{\circ}$ & $2.19 \mathrm{hPa}$ & Low \\
\hline 28 & CESM1-FASTCHEM & NSF-DOE-NCAR, USA & $0.9^{\circ} \times 1.25^{\circ}$ & $2.19 \mathrm{hPa}$ & Low \\
\hline 29 & CMCC-CM & CMCC, Italy & $0.75^{\circ} \times 0.75^{\circ}(\mathrm{T} 159)$ & $10 \mathrm{hPa}$ & Low \\
\hline 30 & CNRM-CM5 & $\begin{array}{l}\text { CNRM-CERFACS, } \\
\text { France }\end{array}$ & $1.4^{\circ} \times 1.4^{\circ}(\mathrm{TL} 127)$ & $10 \mathrm{hPa}$ & Low \\
\hline 31 & CSIRO-Mk3-6-0 & CSIRO-QCCCE, Australia & $1.8^{\circ} \times 1.8^{\circ}$ & $4.5 \mathrm{hPa}$ & Low \\
\hline 32 & FGOALS-g2 & LASG-CESS, China & $2.8^{\circ} \times 2.8^{\circ}$ & $2.19 \mathrm{hPa}$ & Low \\
\hline 33 & FGOALS-s2 & LASG-IAP, China & $2.8^{\circ} \times 1.6^{\circ}$ & $2.19 \mathrm{hPa}$ & Low \\
\hline 34 & FIO-ESM & FIO, China & $2.8^{\circ} \times 2.8^{\circ}$ & $2.19 \mathrm{hPa}$ & Low \\
\hline 35 & GFDL-ESM2G & NOAA GFDL, USA & $2.5^{\circ} \times 2.0^{\circ}$ & $3 \mathrm{hPa}$ & Low \\
\hline 36 & GFDL-ESM2 M & NOAA GFDL, USA & $2.5^{\circ} \times 2.0^{\circ}$ & $3 \mathrm{hPa}$ & Low \\
\hline 37 & HadCM3 & MOHC, UK & $3.75^{\circ} \times 2.5^{\circ}(\mathrm{N} 48)$ & $10 \mathrm{hPa}$ & Low \\
\hline 38 & HadGEM2-AO & MOHC, UK & $1.875^{\circ} \times 1.25^{\circ}(\mathrm{N} 96)$ & $40 \mathrm{~km}$ & Low \\
\hline 39 & HadGEM2-ES & MOHC, UK & $1.875^{\circ} \times 1.25^{\circ}$ & $40 \mathrm{~km}$ & Low \\
\hline 40 & INMCM4 & INM, Russia & $2.0^{\circ} \times 1.5^{\circ}$ & $10 \mathrm{hPa}$ & Low \\
\hline 41 & MIROC5 & MIROC, Japan & $1.41^{\circ} \times 1.41^{\circ}(\mathrm{T} 85)$ & $3 \mathrm{hPa}$ & Low \\
\hline 42 & NorESM1-M & NCC, Norway & $2.5^{\circ} \times 1.9^{\circ}$ & $3.54 \mathrm{hPa}$ & Low \\
\hline
\end{tabular}

The models information is adopted from http://esgf.org/wiki/Cmip5Status and http://pcmdi-cmip.llnl.gov/cmip5/availability.html 
Table 2 Information of the CMIP3 (IPCC-AR4) coupled models used in this paper. The models information is adopted from Randall et al. (2007)

\begin{tabular}{|c|c|c|c|c|c|}
\hline Model No & Model name & Institute and country & Atmospheric model resolution & Atmospheric model lid Top & $\mathrm{L} / \mathrm{H}$ top \\
\hline 1 & BCCR_BCM2.0 & BCCR, Norway & T63L31 & $10 \mathrm{hPa}$ & Low \\
\hline 2 & CGCM3.1(T47) & CCCMA, Canada & $\left(\sim 2.8^{\circ} \times 2.8^{\circ}\right) \mathrm{T} 47 \mathrm{~L} 31$ & $1 \mathrm{hPa}$ & Low \\
\hline 3 & CGCM3.1(T63) & CCCMA, Canada & $\left(\sim 1.9^{\circ} \times 1.9^{\circ}\right) \mathrm{T} 63 \mathrm{~L} 31$ & $1 \mathrm{hPa}$ & Low \\
\hline 4 & CNRM_CM3 & CNRM, France & $\left(\sim 1.9^{\circ} \times 1.9^{\circ}\right) \mathrm{T} 63 \mathrm{~L} 45$ & $0.05 \mathrm{hPa}$ & High \\
\hline 5 & CSIRO_MK3.0 & CSIRO, Australia & $\left(\sim 1.9^{\circ} \times 1.9^{\circ}\right) \mathrm{T} 63 \mathrm{~L} 18$ & $4.5 \mathrm{hPa}$ & Low \\
\hline 6 & CSIRO_MK3_5 & CSIRO, Australia & $\left(\sim 1.9^{\circ} \times 1.9^{\circ}\right) \mathrm{T} 63 \mathrm{~L} 18$ & $4.5 \mathrm{hPa}$ & Low \\
\hline 7 & GFDL_CM2.0 & NOAA GFDL,USA & $\left(2.0^{\circ} \times 2.5^{\circ}\right) \mathrm{L} 24$ & $3 \mathrm{hPa}$ & Low \\
\hline 8 & GFDL_CM2.1 & NOAA GFDL,USA & $\left(2.0^{\circ} \times 2.5^{\circ}\right) \mathrm{L} 24$ & $3 \mathrm{hPa}$ & Low \\
\hline 9 & GISS_AOM & NASA GISS, USA & $\left(3.0^{\circ} \times 4.0^{\circ}\right) \mathrm{L} 12$ & $10 \mathrm{hPa}$ & Low \\
\hline 10 & GISS_EH & NASA GISS, USA & $\left(4.0^{\circ} \times 5.0^{\circ}\right) \mathrm{L} 20$ & $0.1 \mathrm{hPa}$ & High \\
\hline 11 & GISS_ER & NASA GISS, USA & $\left(4.0^{\circ} \times 5.0^{\circ}\right) \mathrm{L} 20$ & $0.1 \mathrm{hPa}$ & High \\
\hline 12 & IAP_FGOALS1.0_G & LASG/IAP, China & $\left(\sim 2.8^{\circ} \times 2.8^{\circ}\right) \mathrm{T} 42 \mathrm{~L} 26$ & $2.2 \mathrm{hPa}$ & low \\
\hline 13 & INGV_ECHAM4 & INGV, Italy & $\left(\sim 1.1^{\circ} \times 1.1^{\circ}\right) \mathrm{T} 106 \mathrm{~L} 19$ & $10 \mathrm{hPa}$ & Low \\
\hline 14 & INM-CM3.0 & INM, Russia & $\left(4.0^{\circ} \times 5.0^{\circ}\right) \mathrm{L} 21$ & $10 \mathrm{hPa}$ & Low \\
\hline 15 & IPSL-CM4 & IPSL, France & $\left(2.5^{\circ} \times 3.75^{\circ}\right) \mathrm{L} 19$ & $4 \mathrm{hPa}$ & Low \\
\hline 16 & MIROC3.2_HIRES & CCSR/JAMSTEC, Japan & $\left(\sim 1.1^{\circ} \times 1.1^{\circ}\right) \mathrm{T} 106 \mathrm{~L} 56$ & $40 \mathrm{~km}$ & Low \\
\hline 17 & MIROC3.2_MEDRES & CCSR/JAMSTEC, Japan & $\left(\sim 2.8^{\circ} \times 2.8^{\circ}\right) \mathrm{T} 42 \mathrm{~L} 20$ & $30 \mathrm{~km}$ & Low \\
\hline 18 & MIUB_ECHO_G & MIUB/KM, Germany/Korea & $\left(\sim 3.9^{\circ} \times 3.9^{\circ}\right) \mathrm{T} 30 \mathrm{~L} 19$ & $10 \mathrm{hPa}$ & Low \\
\hline 19 & MPI_ECHAM5 & MPI, Germany & $\left(\sim 1.9^{\circ} \times 1.9^{\circ}\right) \mathrm{T} 63 \mathrm{~L} 31$ & $10 \mathrm{hPa}$ & Low \\
\hline 20 & MRI_CGCM2.3.2 & MRI, Japan & $\left(\sim 2.8^{\circ} \times 2.8^{\circ}\right) \mathrm{T} 42 \mathrm{~L} 30$ & $0.4 \mathrm{hPa}$ & High \\
\hline 21 & NCAR_CCSM3.0 & NCAR, USA & $\left(\sim 1.4^{\circ} \times 1.4^{\circ}\right) \mathrm{T} 85 \mathrm{~L} 26$ & $2.2 \mathrm{hPa}$ & Low \\
\hline 22 & NCAR_PCM1 & NCAR, USA & $\left(\sim 2.8^{\circ} \times 2.8^{\circ}\right) \mathrm{T} 42 \mathrm{~L} 26$ & $2.2 \mathrm{hPa}$ & Low \\
\hline 23 & UKMO-HADCM3 & MOHC, UK & $\left(2.5^{\circ} \times 3.75^{\circ}\right) \mathrm{L} 19$ & $5 \mathrm{hPa}$ & Low \\
\hline 24 & UKMO_HADGEM1 & MOHC, UK & $\left(\sim 1.3^{\circ} \times 1.9^{\circ}\right) \mathrm{L} 38$ & $39.2 \mathrm{~km}$ & Low \\
\hline
\end{tabular}

(a) SAT DJF $0^{\circ} \mathrm{C}$

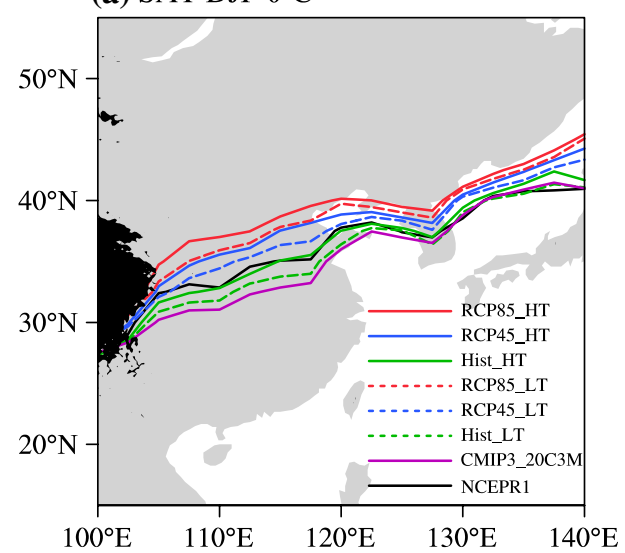

Fig. 1 The comparison of CMIP5 historical run (green, 1970-1999 climatology), RCP45 run (blue, 2070-2099 climatology) and RCP85 run (red, 2070-2099 climatology) between HT models (solid contours) and LT models (dashed contours), together with CMIP3 (b) SLP DJF 1026hPa

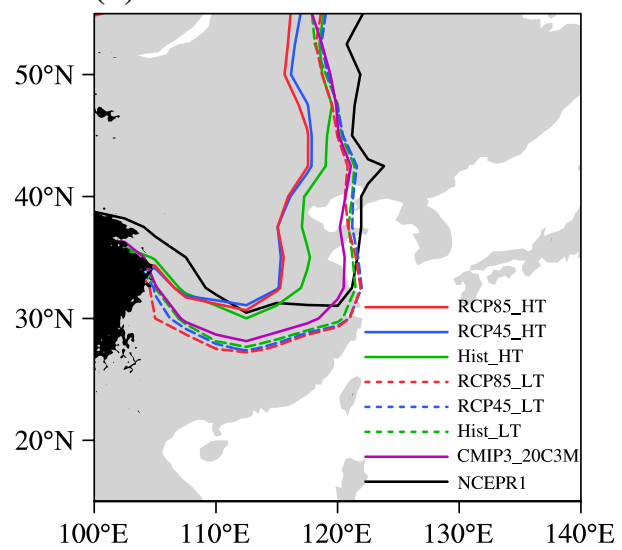

20C3 M run (purple) and NCEPR1 reanalysis (black, 1970-1999 climatology) for EAWM fields: a the mean position of surface temperature (SAT) $0{ }^{\circ} \mathrm{C}$ isotherms; $\mathbf{b}$ sea level pressure represented by 1026-hPa isobars 
Fig. 2 The DJF precipitation rate (unit: $\mathrm{mm} /$ day): a NOAA's Precipitation Reconstruction data (1970-1999 climatology); b CMIP3 MME (1970-1999 climatology); c the differences between CMIP5 models (historical run) and CMIP3 models (20C3 M run); d the differences between CMIP5 HT and LT models in historical run (1970-1999 climatology); e the differences between CMIP5 HT and LT models in RCP45 run (the 2070-2099 climatology); and $\mathbf{f}$ the differences between CMIP5 HT and LT models in RCP85 run (the 2070-2099 climatology). The units are $\mathrm{mm} /$ day in all panels. Dots signify statistically significant regions above the 5\% level according to the Student's $t$ test (a) pr DJF NOAA

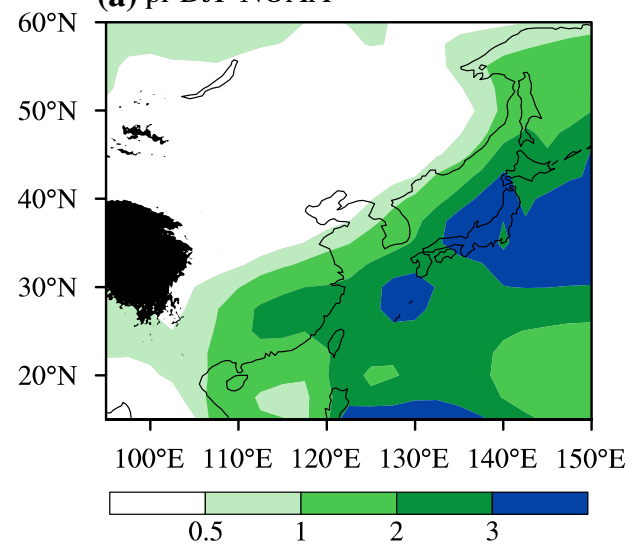

(c) pr DJF (CMIP5-CMIP3)

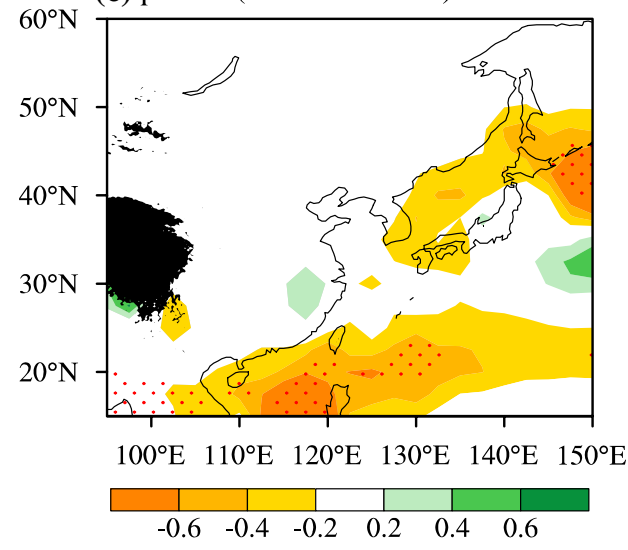

(e) pr DJF RCP45 (HT-LT)

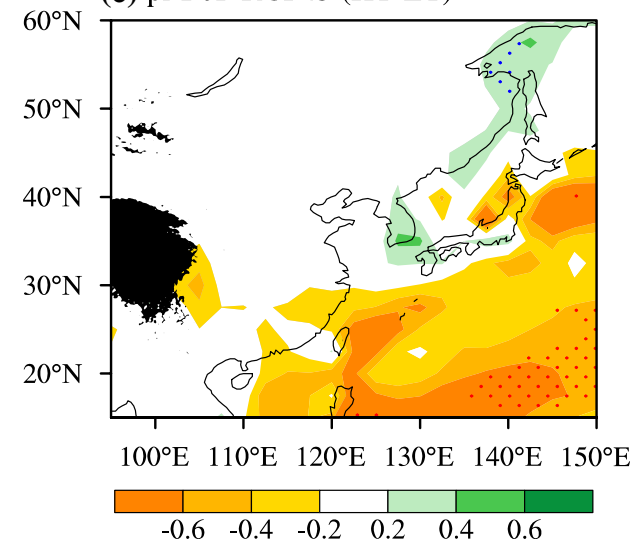

(b) pr DJF CMIP3

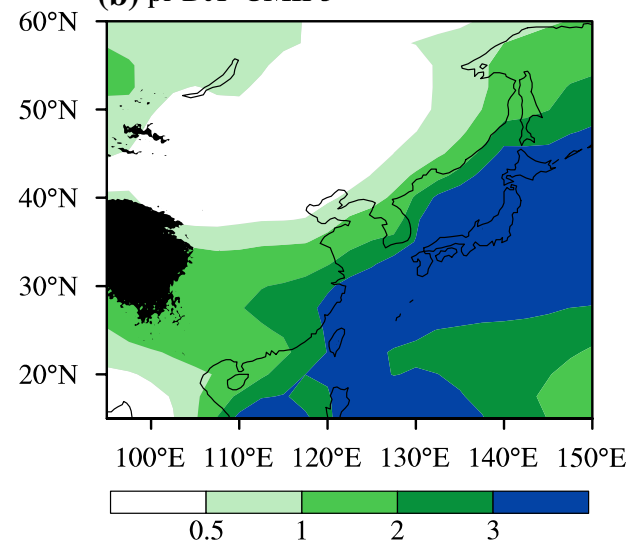

(d) pr DJF Hist (HT-LT)

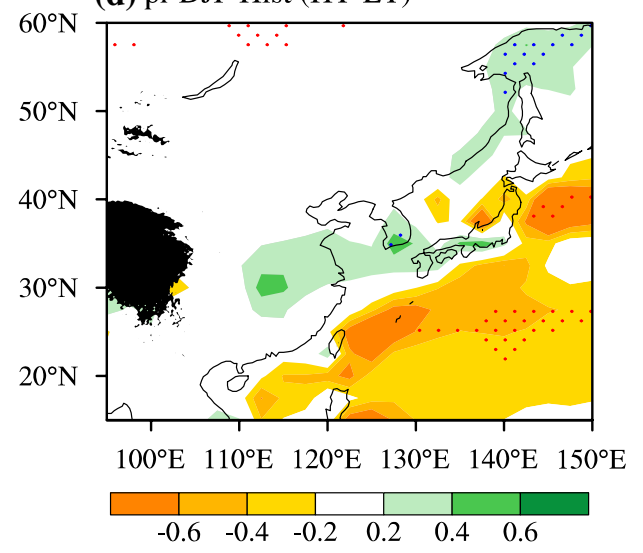

(f) pr DJF RCP85 (HT-LT)

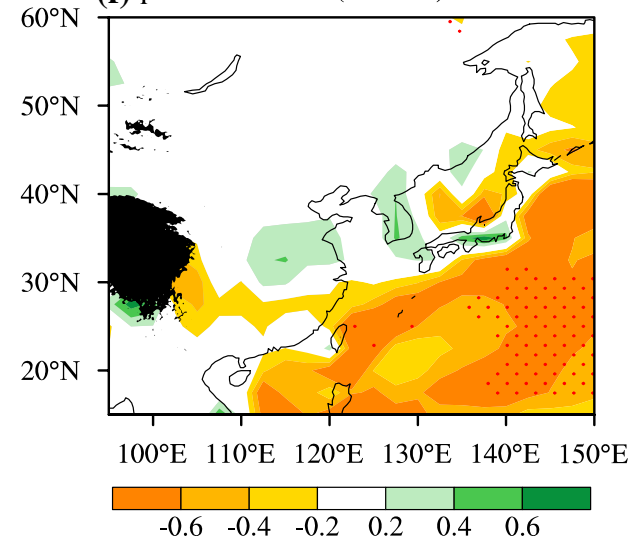

the cold bias is still obvious in the CMIP5 LT models. As the $0{ }^{\circ} \mathrm{C}$ line define the appropriate southern boundary of the snowfield, a better simulation and northward withdraw of the SAT field help to better characterize the hydrological cycle and radiation energy budget in EA region.

The EAWM is characterized by a southward extension of surface cold air and the Siberian High downstream of the Tibetan Plateau over eastern China. The simulation of the SLP (Fig. 1b) shows that the CMIP3 MME is featured with too southward extension of the Siberian High over eastern China. The 1026-hPa isobar of CMIP3 is almost two degree south of the NCEPR1 reanalysis. The similar results can be obtained if utilizing another isobar such as 1024 or $1028 \mathrm{hPa}$ (figures not shown). In CMIP5 LT model historical run (the green dashed line), the too southward extension of the Siberian High is maintained, indicating these models' deficiency in characterizing the sea level pressure distribution. While the southern boundary of the SLP 1026-hPa isobar in the CMIP5 HT historical MME is very close to observation, indicating the superiority of the 
Table 3 Information of the 6 EAWM circulation indices

\begin{tabular}{|c|c|c|c|}
\hline Index & Description & Definition & References \\
\hline$I_{\text {TASEC }}$ & The mean TAS over the East Asia & $\begin{array}{l}\text { The TAS averaged for the domain: } 20^{\circ}-60^{\circ} \mathrm{N} \text {, } \\
100^{\circ}-140^{\circ} \mathrm{E}\end{array}$ & Wei et al. (2014) \\
\hline$I_{\text {SLPEC }}$ & The mean SLP over the eastern China & $\begin{array}{l}\text { The SLP averaged for the domain: } 25^{\circ}-40^{\circ} \mathrm{N} \text {, } \\
110^{\circ}-120^{\circ} \mathrm{E}\end{array}$ & Hio and Yoden (2004) \\
\hline$I_{\text {SLPdiff }}$ & The east-west pressure contrast & $\begin{array}{l}\text { The SLP difference between } 110^{\circ} \mathrm{E} \text { and } 160^{\circ} \mathrm{E} \text { aver- } \\
\text { aged from } 10^{\circ} \mathrm{N} \text { to } 60^{\circ} \mathrm{N}\end{array}$ & Guo (1994) \\
\hline$I_{\mathrm{SH}}$ & The strength of siberian high & $\begin{array}{l}\text { The SLP averaged for the domain: } 40^{\circ}-60^{\circ} \mathrm{N} \text {, } \\
80^{\circ}-120^{\circ} \mathrm{E}\end{array}$ & Wu and Wang (2002) \\
\hline$I_{\text {jet }}$ & The $200 \mathrm{hPa}$ East Asian jet strength & $\begin{array}{l}\text { The } 200 \mathrm{hPa} \text { zonal wind averaged for the domain: } \\
30^{\circ}-35^{\circ} \mathrm{N}, 130^{\circ}-160^{\circ} \mathrm{E}\end{array}$ & Yang et al. (2002) \\
\hline$I_{\mathrm{v}}$ & $\begin{array}{l}\text { The average low-level meridional wind along the EA } \\
\text { coastal region }\end{array}$ & $\begin{array}{l}\text { The } 1000 \mathrm{hPa} \text { northerly averaged for the domain: } \\
15^{\circ}-30^{\circ} \mathrm{N}, 115^{\circ}-130^{\circ} \mathrm{E}\end{array}$ & Ji et al. (1997) \\
\hline
\end{tabular}

HT models in characterizing the southern boundary of the Siberian High. However, the SLP contracts too westward in HT models, compared with the LT models and NCEPR1 reanalysis.

The DJF precipitation distribution in East Asia shows most rainfall in the southeast coastal region, and decreases northwestward and northward. The rain belt above $2 \mathrm{~mm} /$ day extends northeastward from southeast China to Japan, with its eastern margin extending into the North Pacific storm track. The maximum rainfall centers above $3 \mathrm{~mm} /$ day over southwest Japan and central Japan. As WEI14 pointed out, the winter precipitation is overestimated by both CMIP3 and CMIP5 MME over most East Asian region, and the CMIP5 makes great improvement with less rainfall over the East Asia oceanic region of South China Sea, and Sea of Japan (Fig. 2c). The difference between CMIP5 HT and LT historical climatology (Fig. 2d) indicates that HT models have less rainfall over the South China Sea, East China Sea, and the ocean region south of Japan. Therefore, the precipitation amount and pattern are better simulated in the CMIP5 HT models. The overall improvement of the CMIP5 in simulation of precipitation was mainly caused by the improvement of the HT models.

\section{Discrepancy of the EAWM between high-top and low-top CMIP5 models}

In order to assess the performance of CMIP5 models with and without full stratosphere in charactering EAWM, we examined in several key parameters that are usually used as the strength or state of the EAWM. These parameters are listed in Table 3. In Fig. 3, we plotted the above indices in NCEPR1, historical climatology (1970-1999), RCP45 projection (2070-2099), and RCP85 projection (20702099) for HT (red box) and LT (blue box) models. Systematic discrepancy can be observed between HT and LT models under all scenarios. For TAS over East Asian region (Fig. 3a), the HT models present higher temperature than the LT models, which is about $1.2,1.3$ and $1.5{ }^{\circ} \mathrm{C}$ higher than LT models under historical, RCP45 and RCP85. These differences are greater than the standard deviation of the NCEPR1 analysis, which is $0.9{ }^{\circ} \mathrm{C}$. These values are nonignorable, compared with the projected change between the two periods of 1970-1999 and 2070-2099, which are 2.7 and $4.9^{\circ} \mathrm{C}$ under RCP45 and RCP85 in HT models, and 2.6 and $4.6{ }^{\circ} \mathrm{C}$ under RCP45 and RCP85 in LT models.

As for the SLP averaged over the eastern China ( $I_{\text {SLPEC}}$, Fig. 2b), the values of SLP difference between the HT and LT models are much larger than the projected change under all RCPs and in both model groups. This is also true for the strength of Siberian High $\left(I_{\mathrm{SH}}\right.$, Fig. $\left.2 \mathrm{~d}\right)$ and the lowlevel northerly along the southeast China coastal region $\left(I_{\mathrm{V}}\right.$, Fig. 2f). As for the east-west SLP contrast ( $I_{\text {SLPdiff }}$, Fig. 2c), and the $200 \mathrm{hPa}$ jet strength ( $I_{\text {jet }}$, Fig. 2e), the discrepancy between HT and LT models are comparable to the their individual projected change.

Figure 4 shows the difference of SAT and SLP between HT and LT model under historical, RCP45 and RCP85 scenarios. Under all scenarios, the HT models generally simulated higher SAT and lower SLP over the East Asian region than the LT models. The SAT difference is above $1{ }^{\circ} \mathrm{C}$ over most land region. The maximum SAT difference is above 2 degree over Northeast China, Mongolia, and southwest China in historical simulation. It's interesting that the significant and large value regions are almost identical under all the scenarios, suggesting that the mechanism which causing the model discrepancy remains the same. However, the difference is larger over southern China under RCP85 than the RCP45, implying the possible amplifying of the difference between HT and LT by global warming.

The historical SLP difference shows consistent dropping between HT and LT models, while over the Siberian High $(\mathrm{SH})$ center region $\left(40^{\circ}-60^{\circ} \mathrm{N}, 80^{\circ}-120^{\circ} \mathrm{E}\right)$ the SLP 
Fig. 3 Comparison of EAWM climate parameters for $\mathbf{a} I_{\mathrm{TASEC}}$, b $I_{\text {SLPEC }}, \mathbf{c} I_{\text {SLPdiff }}, \mathbf{d} I_{\mathrm{SH}}, \mathbf{e} I_{\text {jet }}$, f $I_{\mathrm{V}}$, the left black boxes are for NCEPR1 reanalysis data with middle value for climatology and upper and lower value for one standard deviation. The blue and red boxes are for CMIP5 LT and HT model climatology, respectively, with middle values for MME, upper and lower values for intra-model standard deviation, and uppermost and lowermost bars for maximum and minimum values (a) TAS East Asia, unit: $\mathrm{K}$

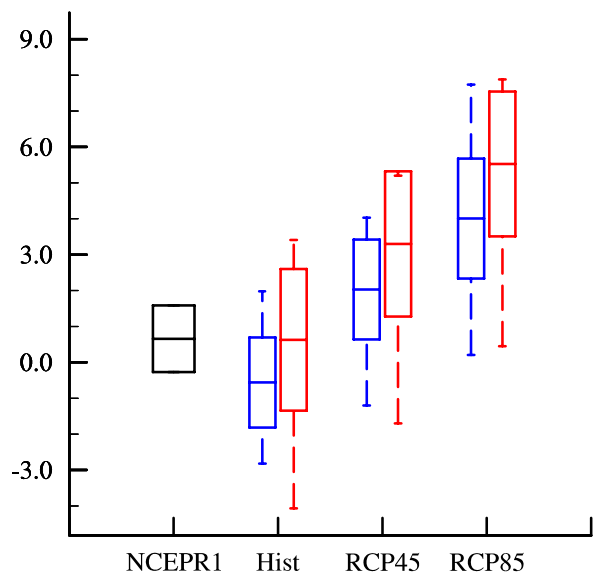

(c) SLP difference $\left(110-160^{\circ} \mathrm{E}\right)$, unit: $\mathrm{hPa}$

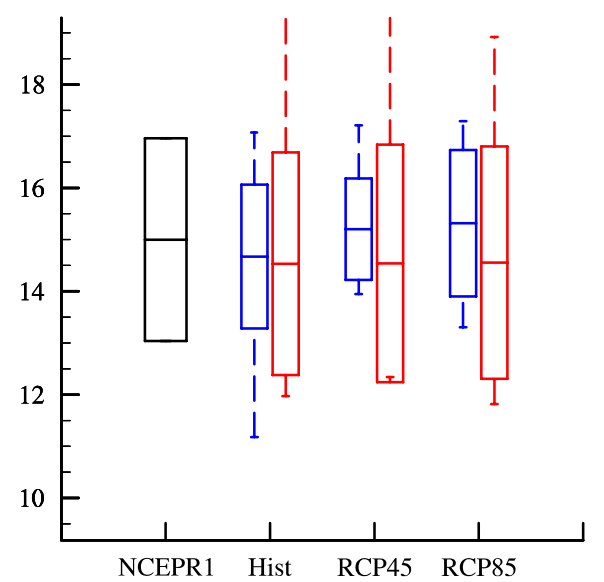

(e) Jet strength $200 \mathrm{hPa}$, unit: $\mathrm{m} \mathrm{s}^{-1}$

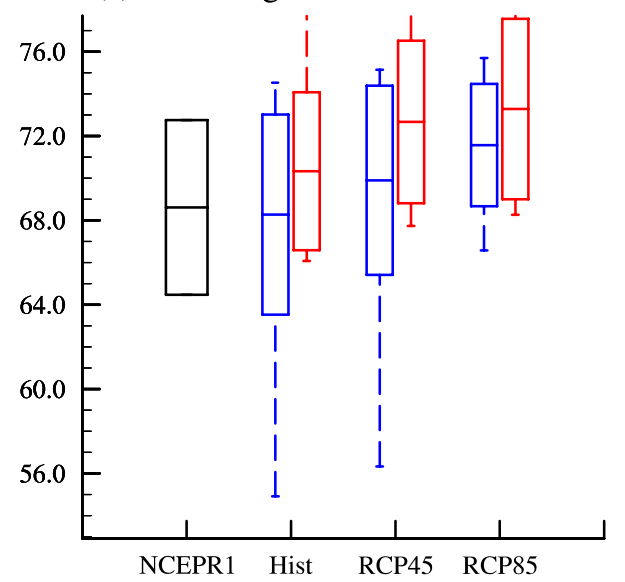

(b) SLP east China, unit: $\mathrm{hPa}$

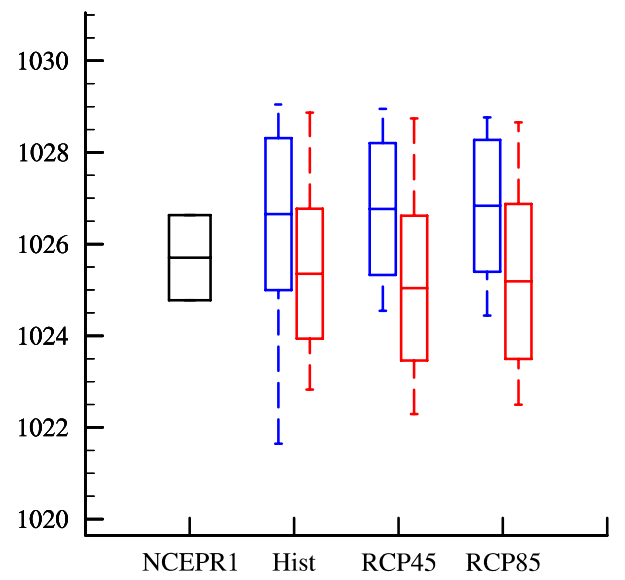

(d) SLP Siberian High, unit: hPa

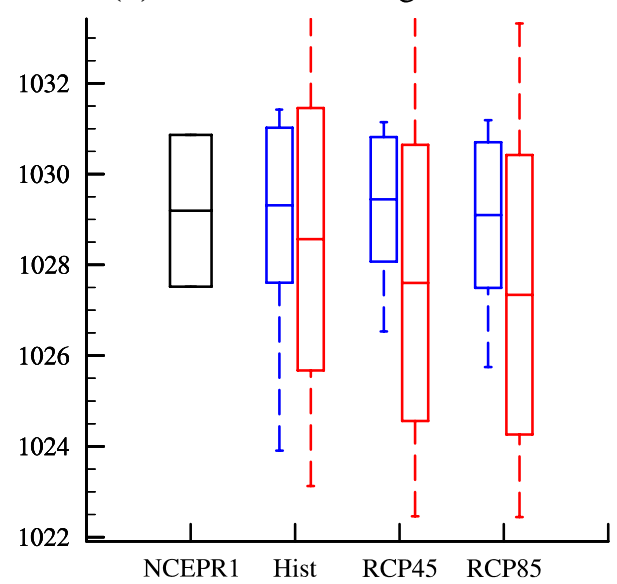

(f) V 1000hPa, unit: $\mathrm{m} \mathrm{s}^{-1}$

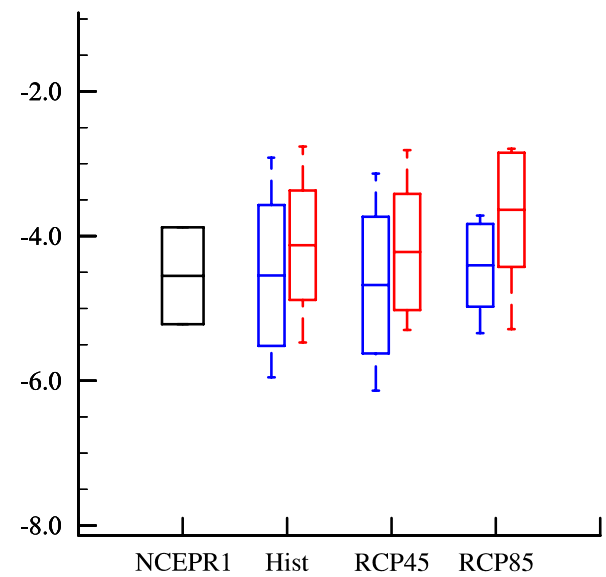

difference value is small, indicating a northward contraction of the Siberian High in the HT models. While under RCPs, the SLP difference between HT and LT groups shows negative anomalies over the $\mathrm{SH}$ center region and East Asia, with the maximum center over North China.

\section{The EAWM projection}

The multi-model ensemble mean SAT (relative to the 1970-1999 base period) over the East Asian region $\left(20^{\circ}\right.$ $\left.60^{\circ} \mathrm{N}, 100^{\circ}-140^{\circ} \mathrm{E}\right)$ through the 21 st century is estimated 


\section{(a) SAT (diff) DJF Hist}

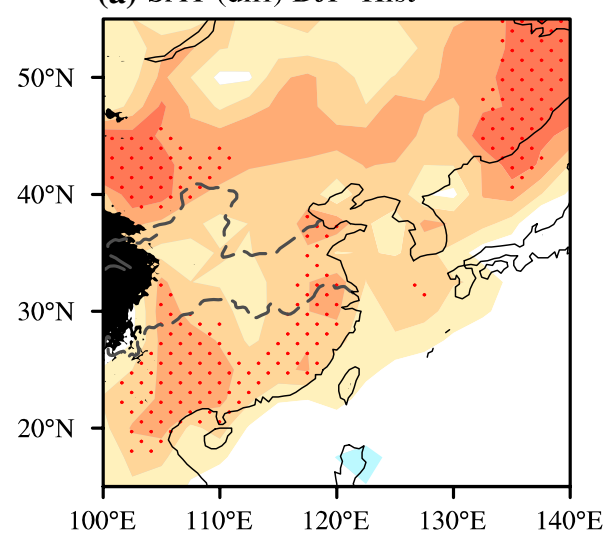

(b) SAT (diff) DJF rcp45

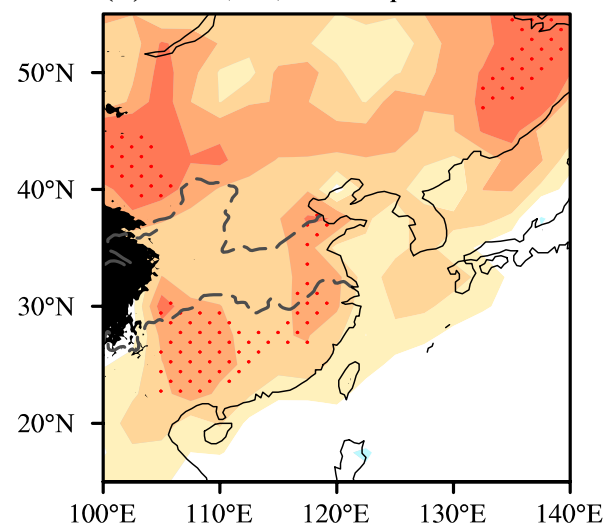

(c) SAT (diff) DJF rcp85

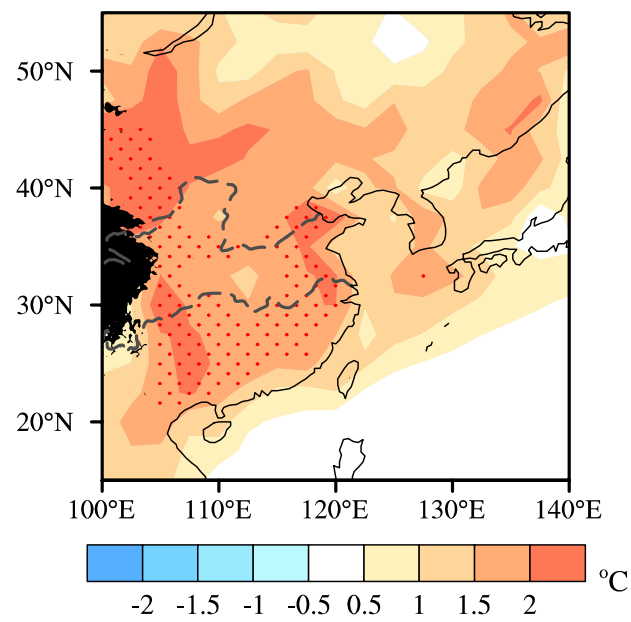

Fig. 4 The differences of surface air temperature (left panels) and sea level pressure (right panels) between CMIP5 HT and LT models under historical (a and d, upper panels, 1970-1999 climatology), RCP45 (b and e, middle panels, 2070-2099 climatology) and RCP85

with CMIP5 HT and LT models under the RCP45 (Fig. 5a) and RCP85 (Fig. 5b) scenarios. The projected SAT in 2100 is $3.2{ }^{\circ} \mathrm{C}$ and $1.9{ }^{\circ} \mathrm{C}$ respectively for HT and LT under $\mathrm{RCP} 45$, and is 6.3 and $4.6{ }^{\circ} \mathrm{C}$ respectively for HT and LT under RCP85. Through the 21 st century, the average (d) SLP (diff) DJF Hist

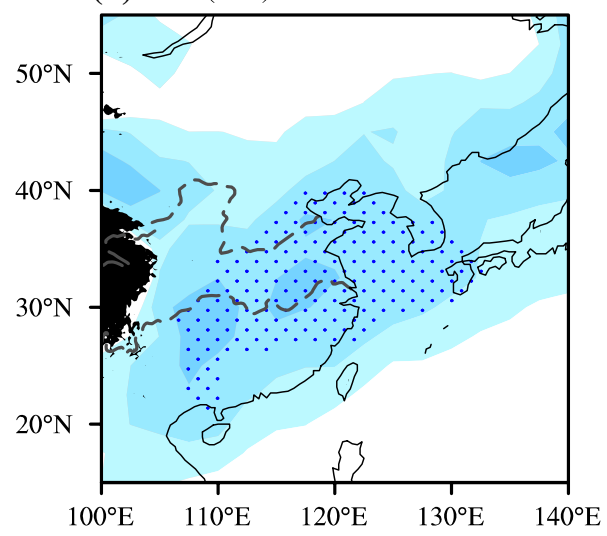

(e) SLP (diff) DJF rcp45

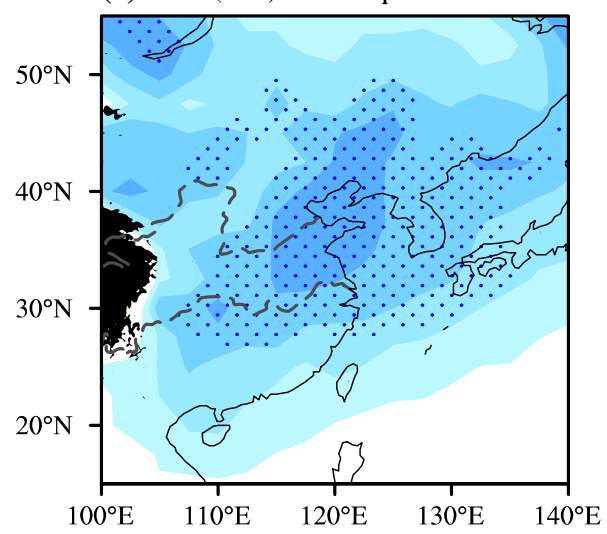

(f) SLP (diff) DJF rcp85

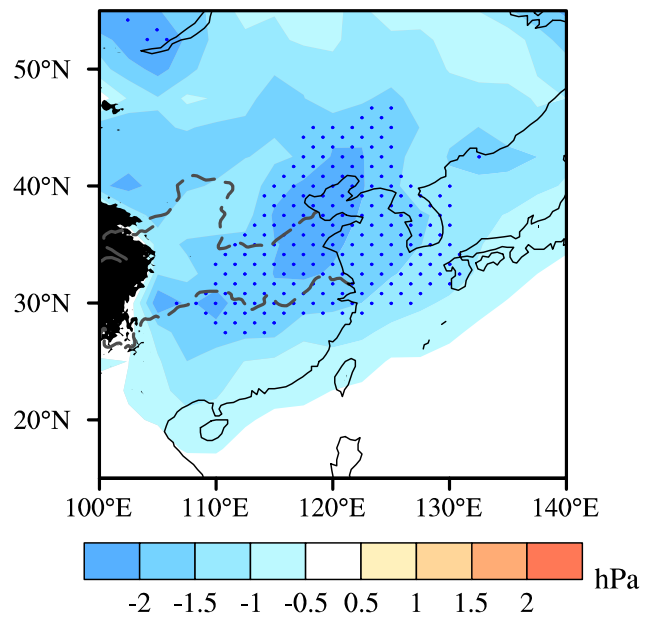

(c and f, bottom panels, 2070-2099 climatology). Dots signify statistically significant regions above the $5 \%$ level according to the Student's $t$ test

difference between HT and LT MME is 1.2 and $1.3{ }^{\circ} \mathrm{C}$ under RCP45 and RCP85, respectively. As the projection of regional and global temperature is usually based on all models regardless of the model stratosphere configuration, this kind of ensemble will get a MME projection around 
Fig. 5 The observed DJF surface air temperautre in East Asian region (the domain: $20^{\circ}-60^{\circ} \mathrm{N}, 100^{\circ}-140^{\circ} \mathrm{E}$ ) since 1961 compared with historical and projection under RCP45 and RCP85 senario senarios for CMIP5 HT and LT models. The black lines are for NCEPR 1 reanalysis, red dashed lines for CMIP5 HT models and blue dotted lines for CMIP5 LT models. The time series from 1961 to 2005 are from the historical run, and the time series from 2006 to 2099 for a RCP45 run and $\mathbf{b}$ RCP85 run. Values are normalised by the NCEPR 1 means from 1961 to 1990. Light grey and orange shades are for the LT and HT models one standard deviation ranges around their multi-model mean, respectively (a) $\mathrm{TAS}(\mathrm{CN}) \mathrm{DJF} \mathrm{RCP} 45$

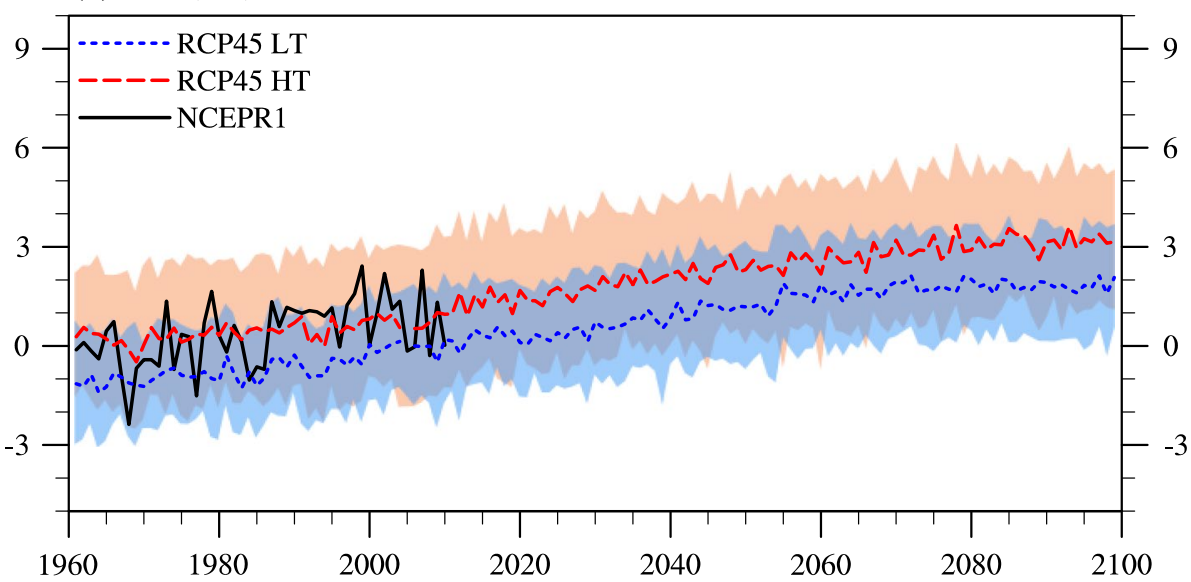

(b) $\mathrm{TAS}(\mathrm{CN}) \mathrm{DJF} \mathrm{RCP} 85$

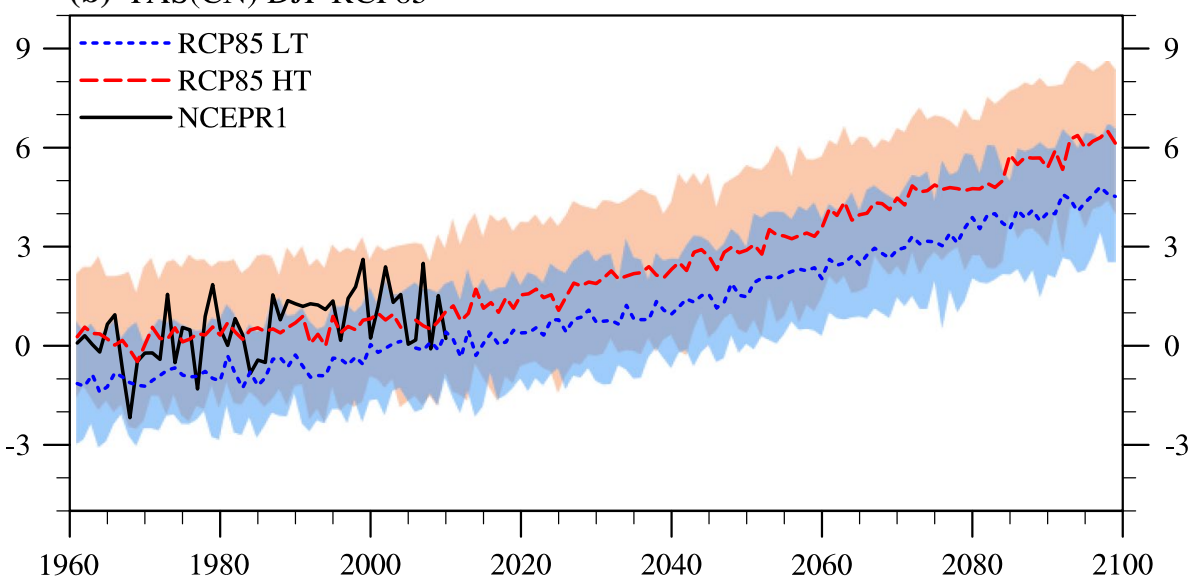

the middle of HT and LT, which is 2.5 and $5.4{ }^{\circ} \mathrm{C}$ under RCP45 and RCP85, respectively. Therefore, the conventional MME results in a relatively lower temperature increase as compared with the full stratosphere-resolved HT models. This lower temperature increase will lead to an underestimation of the SAT change of around $0.7{ }^{\circ} \mathrm{C}$ and $0.9{ }^{\circ} \mathrm{C}$ under the global warming RCP45 and RCP85 scenarios, respectively.

It's worth noting that the projected SAT change of the EA region in both HT and LT groups is comparable to the global SAT change under RCP45 [MME around $1.85{ }^{\circ} \mathrm{C}$ (Acollins et al. 2013)], while is much higher than the global SAT change under RCP85 [MME around $4.15{ }^{\circ} \mathrm{C}$ (Acollins et al. 2013)]. Therefore, it seems that the high emission of RCP85 will be amplified by the seasonal and regional effect. The warming can be extreme in some specific region and season, which worth further study.

The most unanimous change under the global warming scenario in various EAWM parameters (Fig. 3) is the surface air temperature (Fig. 3a) and high-level jet strength (Fig. 3e). In both HT and LT model group, the EA jet stream shows increase tendency, depending on the scenario with higher RCP forcing leading to stronger jet stream. Although the jet stream is considered an important index charactering the state of EAWM, with stronger jet stream corresponding to stronger EAWM, the EAWM doesn't show any systematic strengthening. Another critical component of the EAWM, the Siberian High, shows pronounced SLP decrease in the Siberian High center (Fig. 3d) under RCP45 and RCP85 in the HT models. Meanwhile, the $1000 \mathrm{hPa}$ northerly along the EA coastal region, averaged for the domain of $15^{\circ}-30^{\circ} \mathrm{N}, 115^{\circ}-130^{\circ} \mathrm{E}$, is featured with slightly decrease under RCP85 in the HT models. The zonal SLP gradient (Fig. 3c) doesn't have any discernible change under RCP85 and RCP45 in the HT models. We will discuss in the next section that this kind of jet increase is the response of anthropogenic global warming, instead of a local monsoon system change.

\section{Discussion and conclusions}

In this study, we compared the simulation and projection of the EAWM by two subensembles of the full CMIP5 
(a) $\mathrm{Z} 30 \mathrm{hPa}$ Hist. $\mathrm{Cl}=20 \mathrm{gpm}$

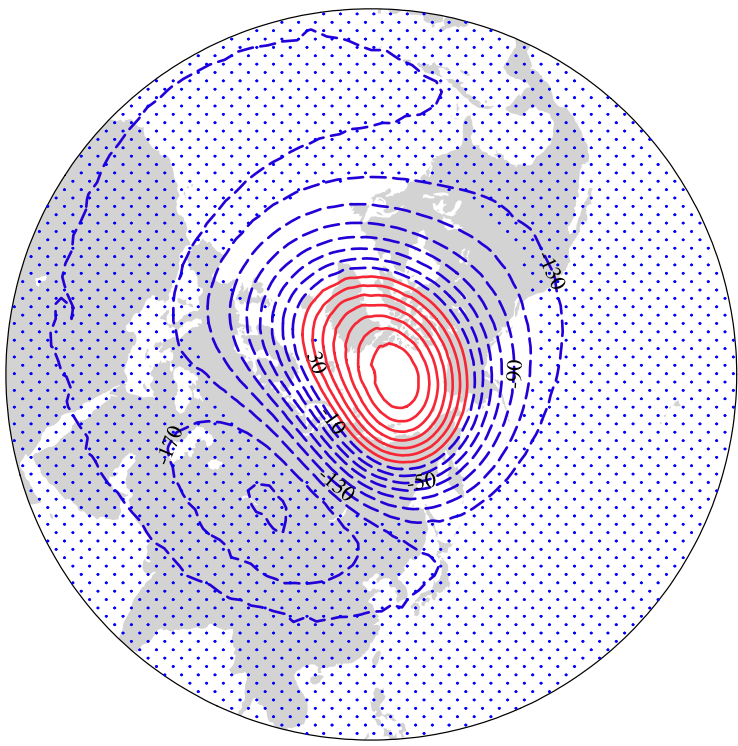

(c) $\mathrm{Z} 850 \mathrm{hPa}$ Hist. $\mathrm{Cl}=10 \mathrm{gpm}$

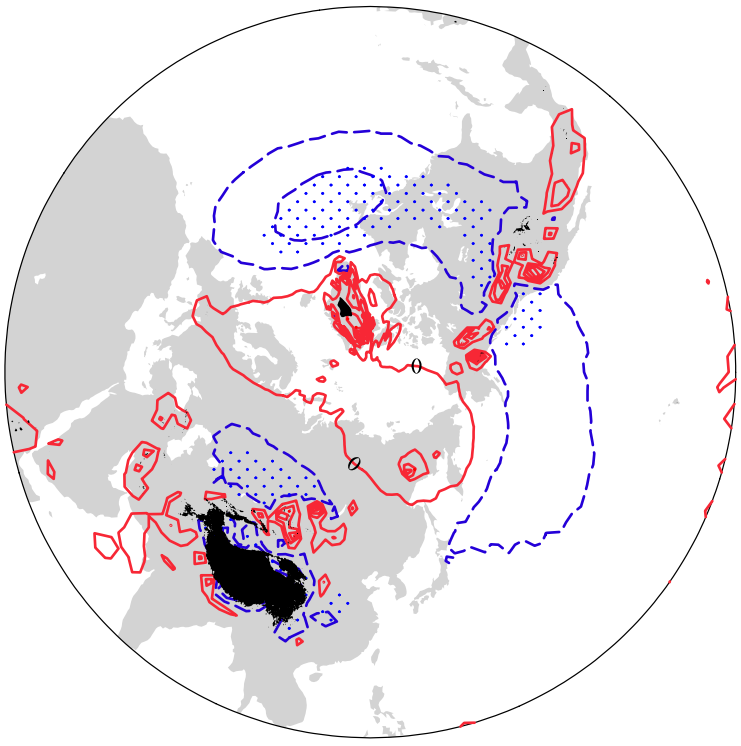

(b) $\mathrm{Z} 100 \mathrm{hPa}$ Hist. $\mathrm{Cl}=10 \mathrm{gpm}$

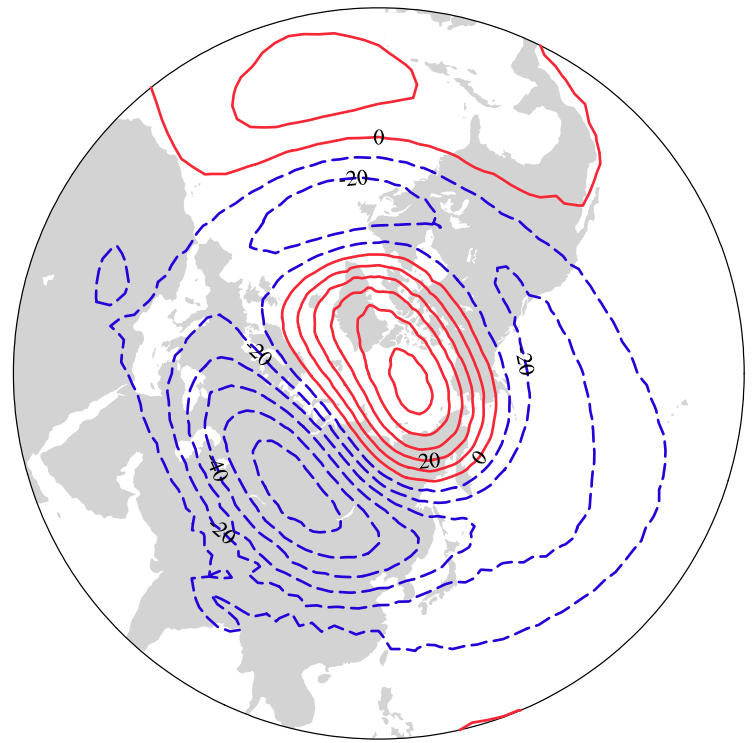

(d) SLP Hist. $\mathrm{Cl}=1 \mathrm{hPa}$

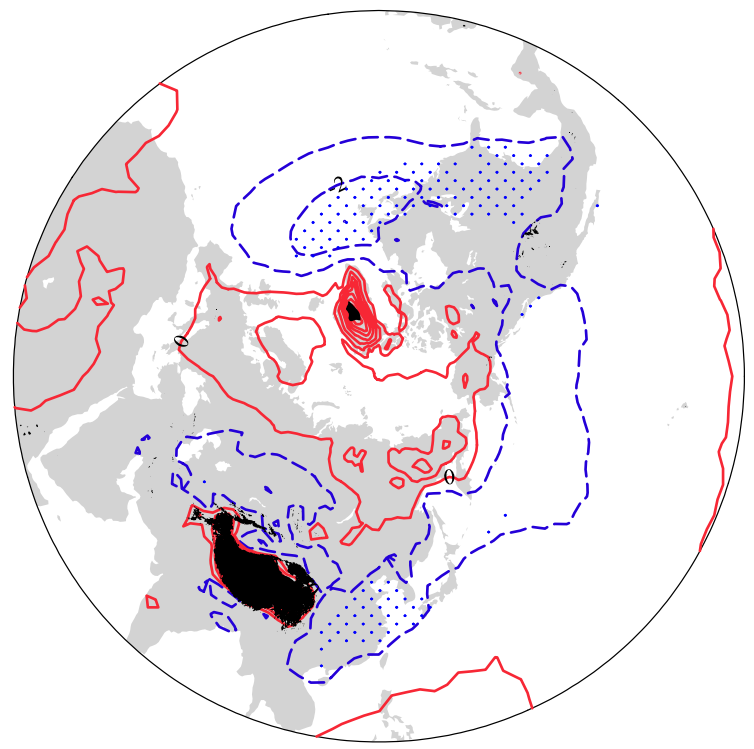

goy is based on the data between 1970 and 1999. Dots signify statistically significant regions above the 5\% level according to the Student's $t$ test

regional winter climate depends largely on the inclusion of a full stratosphere in the coupled model.

With a full stratosphere, the boundary effect in the stratosphere can be alleviated and a real stratospheric polar vortex can be obtained. Studies revealed that, with high-top model, the common cold bias of the stratospheric polar vortex is corrected and the strength of the polar jet is weakened to be comparable to observation (Charlton-Perez et al. 2013). Figure 6 shows the difference of geopotential height at various vertical levels between HT and LT model under 
(a) U\&EPflux diff.(HT-LT) Hist

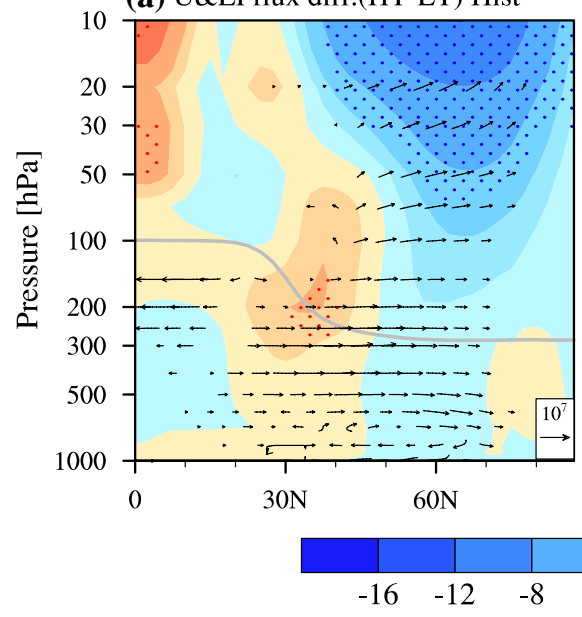

(b) U\&EPflux diff.(HT-LT) rcp45

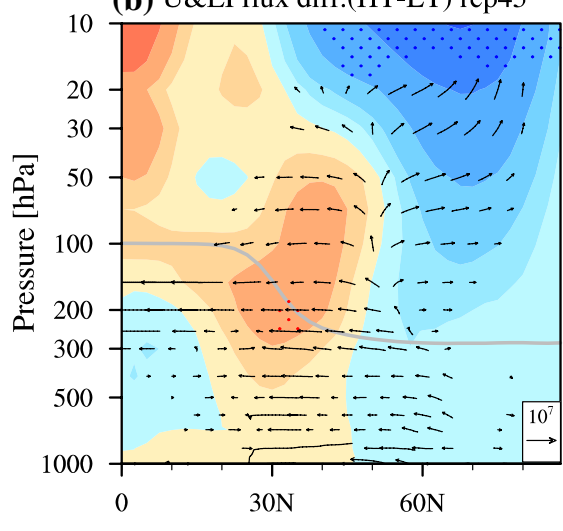

(c) U\&EPflux diff.(HT-LT) rcp85

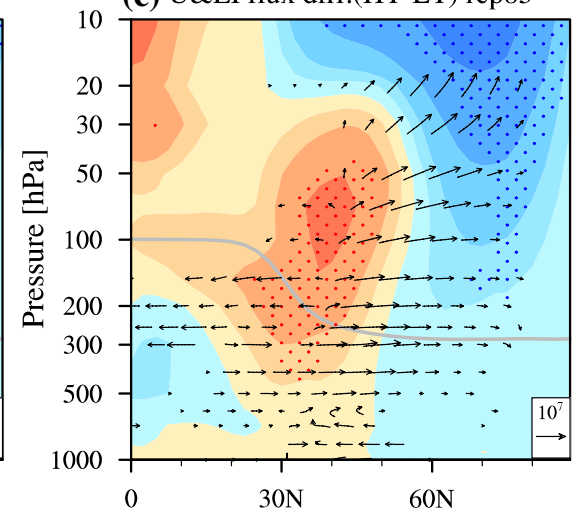

$\mathrm{m} \mathrm{s}^{-1}$

Fig. 7 The zonal-mean zonal wind (shadings) and Eliassen-Palm (EP) flux (vectors) between CMIP5 HT and LT models under a historical (1970-1999 climatology), RCP45 (2070-2099 climatology) and RCP85 (2070-2099 climatology). Dots signify statistically sig- nificant regions above the 5\% level according to the Student's $t$ test for the zonal-mean zonal wind. The EP fluxes are scaled by the inverse of the square root of the air density and the unit is $\mathrm{kg} \mathrm{s}^{-2}$ the historical run. The meridional geopotential height gradient is decreased around the stratospheric polar vortex in the MME of HT models, with height increase in the polar cap and significant height decrease in the middle latitudes and the sub-polar region. This north-south geopotential height anomaly makes a negative North Annular Model (NAM) pattern and has a deep quasi-barotropic influence through the height of stratosphere and troposphere. At the lower levels of $850 \mathrm{hPa}$ and the sea level, the polar region pressure is increased, while the pressure around the middle latitude is decreased. Meanwhile, at the middle stratosphere level (Fig. 6a), a wavy pattern of wavenumber 1 is apparent. And at the low tropospheric level, the SLP over Siberia, East Asia, North America, and North Atlantic is decreased, making a wavy pattern of wavenumber 2 . The SLP decreases over the Siberia and East Asia region. The circulation change favors the weakening of the EAWM and therefore leads to the SAT increase in the East Asian region.

The zonal-mean zonal wind difference (Fig. 7a) between HT and LT models shows zonal wind reduction around the polar throughout the stratosphere and troposphere, while wind increase in the upper troposphere and lower stratosphere around $35^{\circ} \mathrm{N}$, centering on the subtropical tropopause. This wind change may be associated with the change of planetary wave in the stratosphere-troposphere system. The HT ensemble has a stronger stratospheric wave-guide than the LT ensemble, while its tropospheric wave-guide is slightly weaker than the LT models. According to Chen et al. (2003), this kind of dipole structure in Eliassen-Palm (EP) flux (Andrews et al. 1987; Edmon et al. 1980) anomalies could lead to the weakening of the polar night jet and the strengthening of the subtropical jet. The polar jet and subtropical jet change under the RCPs have the similar pattern, indicating that the dynamical mechanism of including a full stratosphere remains the same. However, it should bet noted that model's sensitivity to increase of greenhouse gases may increase the subtropical jet. The greenhouse gas-associated global warming causes a mixing of tropospheric warming and stratospheric cooling. Since the tropopause has an average height of $\sim 17 \mathrm{~km}$ in the tropics and only $\sim 9 \mathrm{~km}$ at the poles, both the temperature and pressure gradients increases near the upper troposphere and lower stratosphere in the subtropical regions, leading to zonal wind acceleration from upper troposphere to middle stratosphere there. The subtropical jet increase of the HT models indicates that the models with a full stratosphere are more capable of capturing the GHG-associated global change signal. Accordingly, the subtropical jet gets stronger in the HT models, especially under the high emission RCP85 scenario.

Currently, the models with full stratosphere are usually featured with higher model top above stratopause, as well as non-orographic gravity waves (NOGW). In this study, 17 of the 20 HT models considered NOGW, and only 5 of the 22 LT models have the NOGW. Meanwhile, most (12 of the 20 models) of the HT models considered the carbon cycle and natural aerosols and therefore belongs to Earth system models (ESMs), while half (11 of the 22 models) of the LT models are ESMs. Therefore, the inclusion of the NOGW and upgrade to ESMs may also help to improve the simulation of stratospheric polar vortex and the EAWM.

The projection under RCP scenarios shows significant discrepancy between HT and LT models. Under the 
midrange emission RCP45 scenario, the projected SAT change in 2100 over the EA region is 3.2 and $1.9^{\circ} \mathrm{C}$ for HT and LT models, respectively. And it's $6.3{ }^{\circ} \mathrm{C}(\mathrm{HT})$ and $4.6{ }^{\circ} \mathrm{C}$ (LT) in 2100 under the higher emission RCP85 scenario. Therefore, the conventional MME using both HT and LT models will lead to lower temperature increase than the full stratosphere-resolved models ensemble. As climate models have now become one of the primary tools in climate change assessment and projection, which was used as the base for mitigation measure and adaption policy. The systemic underestimation of the temperature change in the LT climate models have the potential to lead to insufficient response action to the anthropogenic global warming in the next decades.

Although our study focuses on the EA region in the cold season, it's worth to note that the stratosphere configuration in the climate model can have significant influence in other seasons and regions. The involvement of a full stratosphere results in a better simulation of the global-scale stratospheric polar vortex, which can have global influences. And the amplitude of global change under RCP scenarios may be different from current evaluation. This will be discussed in another study.

Acknowledgements This research is supported by the National key research and development project of China (Grant No. 2016YFA0600600), the National Natural Science Foundation of China (Grant No. 41375046) and the Youth Innovation Promotion Association of Chinese Academy of Sciences (No. 2014064).

Open Access This article is distributed under the terms of the Creative Commons Attribution 4.0 International License (http://creativecommons.org/licenses/by/4.0/), which permits unrestricted use, distribution, and reproduction in any medium, provided you give appropriate credit to the original author(s) and the source, provide a link to the Creative Commons license, and indicate if changes were made.

\section{References}

Acollins M et al (2013) Long-term climate change projections, commitments and irreversibility. In: Stocker TF et al (eds) Climate change 2013: the physical science basis contribution of working group I to the fifth assessment report of the intergovernmental panel on climate change. Cambridge University Press, Cambridge, New York, NY, pp 1029-1136

Andrews DG, Holton JR, Leovy CB (1987) Middle atmosphere dynamics. Academic Press, New York, NY, p 489

Baldwin MP, Dunkerton TJ (1999) Propagation of the Arctic Oscillation from the stratosphere to the troposphere. J Geophys Res 104:30937-30946. doi:10.1029/1999JD900445

Baldwin MP, Dunkerton TJ (2001) Stratospheric harbingers of anomalous weather regimes. Science 294:581-584. doi:10.1126/ science. 1063315

Baldwin MP et al (2001) The quasi-biennial oscillation. Rev Geophys 39:179-229

Baldwin MP, Thompson DWJ, Shuckburgh EF, Norton WA, Gillett NP (2003a) Weather from the stratosphere? Science 301:317-319
Baldwin MP, Stephenson DB, Thompson DWJ, Dunkerton TJ, Charlton AJ, O'Neill A (2003b) Stratospheric memory and skill of extended-range weather forecasts. Science 301:636-640. doi:10.1126/science. 1087143

Boo K-O, Martin G, Sellar A, Senior C, Byun Y-H (2011) Evaluating the East Asian monsoon simulation in climate models. J Geophys Res. doi:10.1029/2010jd014737

Butler AH et al (2016) The Climate-system Historical Forecast Project: do stratosphere-resolving models make better seasonal climate predictions in boreal winter? Q J R Meteorol Soc 142:1413-1427. doi:10.1002/qj.2743

Charlton-Perez AJ et al (2013) On the lack of stratospheric dynamical variability in low-top versions of the CMIP5 models. J Geophys Res 118:2494-2505. doi:10.1002/jgrd.50125

Chen MY, Xie PP, Janowiak JE, Arkin PA (2002) Global land precipitation: a 50-yr monthly analysis based on gauge observations. J Hydrometeorol 3:249-266. doi:10.1175/1525-7541(2002)003<0249:glpaym>2.0.co;2

Chen W, Takahashi M, Graf HF (2003) Interannual variations of stationary planetary wave activity in the northern winter troposphere and stratosphere and their relations to NAM and SST. J Geophys Res 108:4797. doi:10.1029/2003JD003834

Christiansen B (2001) Downward propagation of zonal mean zonal wind anomalies from the stratosphere to the troposphere: model and reanalysis. J Geophys Res 106:27307-27322. doi:10.1029/2 000JD000214

Cordero EC, Forster PMD (2006) Stratospheric variability and trends in models used for the IPCC AR4. Atmos Chem Phys 6:5369-5380

Edmon HJ Jr, Hoskins BJ, McIntyre ME (1980) Eliassen-Palm cross sections for the troposphere. J Atmos Sci 37:2600-2616

Gong H, Wang L, Chen W, Wu R, Wei K, Cui X (2014) The climatology and interannual variability of the East Asian Winter monsoon in CMIP5 models. J Clim 27:1659-1678. doi:10.1175/ jcli-d-13-00039.1

Guo Q (1994) Relationship between the variations of East Asian winter monsoon and temperature anmalies in China. Quart J Appl Meteorol 5:218-225 (in Chinese)

Hio Y, Yoden S (2004) Quasi-periodic variations of the polar vortex in the Southern Hemisphere stratosphere due to wave-wave interaction. J Atmos Sci 61:2510-2527. doi:10.1175/jas3257.1

Holton JR, Lindzen RS (1972) An updated theory for the quasi-biennial cycle of the tropical stratosphere. J Atmos Sci 29:1076-1080

Holton JR, Mass C (1976) Stratospheric vacillation cycles. J Atmos Sci 33:2218-2225. doi:10.1175/1520-0469(1976)033<2218:SVC >2. $0 . \mathrm{CO} ; 2$

Ji L, Sun S, Arpe K, Bengtsson L (1997) Model study on the interannual variability of Asian winter monsoon and its influence. Adv Atmos Sci 14:1-22

Kalnay E et al (1996) The NCEP/NCAR 40-year reanalysis project. Bull Am Meteorol Soc 77:437-471

Karpechko AY, Manzini E (2012) Stratospheric influence on tropospheric climate change in the Northern Hemisphere. J Geophys Res 117. doi:10.1029/2011jd017036

Kistler R et al (2001) The NCEP-NCAR 50-year reanalysis: monthly means CD-ROM and documentation. Bull Am Meteorol Soc $82: 247-268$

Kodera K (1995) On the origin and nature of the interannual variability of the winter stratospheric circulation in the Northern Hemisphere. J Geophys Res 100:14077-14088

Kuroda Y, Kodera K (1999) Role of planetary waves in the stratosphere-troposphere coupled variability in the Northern Hemisphere winter. Geophys Res Lett 26:2375-2378

Labitzke K (1982) On the interannual variability of the middle stratosphere during the northern winters. J Meteorol Soc Jpn 60:124-139 
Lindzen RS, Holton JR (1968) A theory of the quasi-biennial oscillation. J Atmos Sci 25:1095-1107

Manzini E, Cagnazzo C, Fogli PG, Bellucci A, Mueller WA (2012) Stratosphere-troposphere coupling at inter-decadal time scales: implications for the North Atlantic ocean. Geophys Res Lett. doi: $10.1029 / 2011 \mathrm{gl} 050771$

Matsuno T (1971) A dynamical model of the stratospheric sudden warming. J Atmos Sci 28:1479-1494

Moritz RE, Bitz CM, Steig EJ (2002) Dynamics of recent climate change in the Arctic. Science 297:1497-1502. doi:10.1126/ science. 1076522

Osprey SM, Gray LJ, Hardiman SC, Butchart N, Hinton TJ (2013) Stratospheric variability in twentieth-century CMIP5 simulations of the met office climate model: high top versus low top. J Clim 26:1595-1606. doi:10.1175/jcli-d-12-00147.1

Plumb RA (1977) The interaction of two internal waves with the mean flow: implications for the theory of the quasi-biennial oscillation. J Atmos Sci 34:1847-1858

Randall DA et al (2007) Climate models and their evaluation. In: Solomon S et al (eds) Climate change 2007: the physical science basis contribution of working group I to the fourth assessment report of the intergovernmental panel on climate change. Cambridge University Press, Cambridge, New York, NY, pp 589-662
Scaife AA et al (2012) Climate change projections and stratospheretroposphere interaction. Clim Dyn 38:2089-2097. doi:10.1007/ s00382-011-1080-7

Taylor KE, Stouffer RJ, Meehl GA (2012) An overview of CMIP5 and the experiment design. Bull Am Meteorol Soc 93:485-498. doi:10.1175/bams-d-11-00094.1

Wei K, Bao Q (2012) Projections of the East Asian winter monsoon under the IPCC AR5 scenarios using a coupled model: IAP_FGOALS. Adv Atmos Sci 29:1200-1214. doi:10.1007/ s00376-012-1226-5

Wei K, Xu T, Du Z, Gong H, Xie B (2014) How well do the current state-of-the-art CMIP5 models characterise the climatology of the East Asian winter monsoon? Clim Dyn 43:1241-1255. doi:10.1007/s00382-013-1929-z

Wei K, Takahashi M, Chen W (2015) Long-term changes in the relationship between stratospheric circulation and East Asian winter monsoon. Atmos Sci Lett. doi:10.1002/as12.568

Wu B, Wang J (2002) Winter Arctic oscillation siberian high and East Asian winter monsoon. Geophys Res Lett 29:1897. doi:10.1029/ 2002GL015373

Yang S, Lau KM, Kim KM (2002) Variations of the East Asian jet stream and Asian-Pacific-American winter climate anomalies. J Clim 15:306-325 